Research Article

\title{
Essential Oil of Acorus tatarinowii Schott Ameliorates $A \beta$ - Induced Toxicity in Caenorhabditis elegans through an Autophagy Pathway
}

\author{
Xin-yan Chen, De-chun Liao, Meng-lu Sun, Xiang-huan Cui $\mathbb{D}^{D}$, and Hong-bing Wang \\ Putuo District People's Hospital, School of Life Sciences and Technology, Tongji University, Shanghai 200092, China \\ Correspondence should be addressed to Xiang-huan Cui; cuixh@tongji.edu.cn and Hong-bing Wang; hbwang@tongji.edu.cn
}

Received 9 July 2020; Revised 28 October 2020; Accepted 4 December 2020; Published 23 December 2020

Academic Editor: Silvana Hrelia

Copyright (C) 2020 Xin-yan Chen et al. This is an open access article distributed under the Creative Commons Attribution License, which permits unrestricted use, distribution, and reproduction in any medium, provided the original work is properly cited.

\begin{abstract}
Background. Acorus tatarinowii Schott [Shi Chang Pu in Chinese (SCP)] is a traditional Chinese medicine frequently used in the clinical treatment of dementia, amnesia, epilepsy, and other mental disorders. Previous studies have shown the potential efficacy of SCP against Alzheimer's disease (AD). Nevertheless, the active constituents and the modes of action of SCP in AD treatment have not been fully elucidated. Purpose. The aim of this study was to investigate the protective effects of SCP on abnormal proteins and clarify its molecular mechanisms in the treatment of $\mathrm{AD}$ by using a Caenorhabditis elegans (C. elegans) model. Methods. This study experimentally assessed the effect of SCP-Oil in CL4176 strains expressing human $A \beta$ in muscle cells and CL2355 strains expressing human $A \beta$ in pan-neurons. Western blotting, qRT-PCR, and fluorescence detection were performed to determine the oxidative stress and signaling pathways affected by SCP-Oil in nematodes. Results. SCP-Oil could significantly reduce the deposition of misfolded $A \beta$ and polyQ proteins and improved serotonin sensitivity and olfactory learning skill in worms. The analysis of pharmacological action mechanism of SCP-Oil showed that its maintaining protein homeostasis is dependent on the autophagy pathway regulated partly by $h s f-1$ and sir-2.1 genes. Conclusion. Our results provide new insights to develop treatment strategy for AD by targeting autophagy, and SCP-Oil could be an alternative drug for anti-AD.
\end{abstract}

\section{Introduction}

Alzheimer's disease $(\mathrm{AD})$ is an age-related neurodegenerative disorder clinically featuring loss of memory, cognitive, and behavior functions. To date, only donepezil, galantamine, memantine, and rivastigmine have been approved by the United States Food and Drug Administration for the treatment of mild to moderate $\mathrm{AD}$, but these drugs cannot interrupt or halt disease progression [1]. Therefore, more efficacious therapeutic drugs are required for the management of AD. The pathogenesis of Alzheimer's disease is associated with abnormal proteins including $A \beta$ and tau aggregation in the brain. Generally, there is no deposition of $\mathrm{A} \beta$ peptide in the healthy brain, but the increased level of the $\mathrm{A} \beta$ peptide aggregation is manifested in the $\mathrm{AD}$ brain. Growing studies indicated that autophagy contributes to the degradation of abnormal proteins [2]. It has been reported that many medicinal herbs contain promising autophagy regulators and have great therapeutic potential for $\mathrm{AD}$ treatment [3].

Acorus tatarinowii Schott [A. tatarinowii, Shi Chang $\mathrm{Pu}$ in Chinese (SCP)] is a renowned traditional Chinese medicine that was first recorded in the Shennong Materia Medica. It is commonly used in the clinical treatment of dementia, amnesia, epilepsy, and other mental disorders [4]. Earlier studies showed that the essential oil from SCP prevented hydrogen peroxide-induced cell injury in PC12 cells (Yan et al., 2020), and $\beta$-asarone, a major component of SCP, showed protection against oxidative stress and neuronal damage induced by amyloid- $\beta$ in rats $[5,6]$. However, the underlying pharmacological action mechanism of SCP-Oil remains unclear.

In this study, we first used Caenorhabditis elegans (C. elegans) as an in vivo model to elucidate the action mechanism of SCP-Oil. C. elegans is widely used in laboratory research as it is rapidly propagated and has a short life cycle, a simple 
structure, and extensive homology with mammals [7]. Moreover, $C$. elegans can be readily induced by gene editing to express human $A \beta$ in their muscle cells and neurons, so it is considered to be a powerful model for screening $\mathrm{AD}$ related drugs and clarifying their mechanisms [8].

Here, we reported the protection effects of SCP-Oil in a transgenic A $\beta$ C. elegans model. Our results showed that it can reduce ROS accumulation and show protection effects against abnormal $\mathrm{A} \beta$ and polyQ proteins by targeting autophagy degradation pathway. Our findings furtherly prove the potential of SCP-Oil to be used in AD treatment.

\section{Materials and Methods}

2.1. SCP-Oil Extraction and Separation. Acorus tatarinowii Schott (SCP) was purchased from Beijing Tongrentang Co. Ltd. (Shanghai, China). $300 \mathrm{~g}$ dry roots was ground in a high-speed blender and extracted twice by refluxing in 3-5x petroleum ether at $80^{\circ} \mathrm{C}$ for $1 \mathrm{~h}$. The extracts were pooled and concentrated at $50-60^{\circ} \mathrm{C}$ under reduced pressure. The oil extract yield was $6.27 \mathrm{~g}$.

2.2. Strains. The following C. elegans strains were acquired from Caenorhabditis Genetics Center (CGC; Minneapolis, MN, USA; funded by the National Institutes of Health (NIH) Office of Research Infrastructure Programs (P40 OD010440)): CL4176[dvIs27 [myo-3p::Abeta (1-42)::let851(3'UTR $)+$ rol-6(su1006)] X]; CL802[smg-1(cc546) I; rol-6(su1006) II] control for CL4176. CL2355[dvIs50 [pCL45 (snb-1::Abeta(1-42)::3'UTR(long) + mtl-2::GFP] I]; CL2122[dvIs15 [(pPD30.38) unc-54(vector) + (pCL26) mtl2::GFP] control strain for CL2355. BC12921[sIs10729 [rCes T12G3.1::GFP + pCeh361], AM140[rmIs132 [unc54p::Q35::YFP]].

2.3. Strain Maintenance and Treatment. All strains were maintained at $16^{\circ} \mathrm{C}$ except for BC12921 and AM140 which were maintained at $20^{\circ} \mathrm{C}$. The worms were cultured on solid nematode growth medium (NGM) [9] plates containing a lawn of Escherichia Coli (E. coli) OP50 and fed with the drugs from the time they were age-synchronized to adult stage.

2.4. High-Performance Liquid Chromatography (HPLC) of SCP-Oil. A ZORBAX Eclipse XDB C-18 column (Agilent) was used for high-performance liquid chromatography (HPLC) analysis. The operating conditions were as follows: either $10 \mathrm{mg} / \mathrm{mL}$ extract or $1.0 \mathrm{mg} / \mathrm{mL}$ standard; $1.0 \mathrm{~mL} / \mathrm{min}$ flow rate; $10 \mu \mathrm{L}$ injection volume; detection wavelength set at $254 \mathrm{~nm}$; and room temperature $\left(25^{\circ} \mathrm{C}\right)$. The eluents were as follows: A (ultrapure water) and B (100\% ( $v / v)$ methanol). The gradient was as follows: $0.01 \mathrm{~min} 35 \% \mathrm{~B}, 30 \mathrm{~min} 75 \% \mathrm{~B}$, $45 \min 85 \%$ B, $55 \min 95 \%$ B, and $65 \min 95 \%$ B. Prior to their injection in the HPLC, all samples were filtered through a $45-\mu \mathrm{M}$ membrane (Agilent). The analysis result was seen in Supplementary Fig. S2.

2.5. Safety Assessment Assay. Synchronized L1 larvae were cultured in a 96-well plate with OP50, and $1.08 \mathrm{mM}$ FUdR was added by L3. Then, young adult larvae were treated with various concentrations of SCP-Oil. The live worms were observed and recorded daily until day 4 . Nematodes that were stiff and unresponsive to strong light or agitation were assumed to be dead.

2.6. Paralysis Assay in Nematodes. Synchronized L1 larvae (>30 worms per treatment) were transferred to $35 \mathrm{~mm}$ culture plates containing OP50 and drugs, cultured at $16^{\circ} \mathrm{C}$ for $36 \mathrm{~h}$, and upshifted to $23^{\circ} \mathrm{C}$ for transgene induction, scoring the paralyzed worms per hour after cultured at $23^{\circ} \mathrm{C}$ for another $24 \mathrm{~h}$. Worms were considered paralyzed when they fail to move about, did not respond to platinum wire stimulus, or presented with an anterior halo [10]. The assay was repeated at least three times, and the $\mathrm{PT}_{50}$ (time duration in which half worms were paralyzed) was calculated [11].

2.7. Western Blotting. Synchronized L1 worms were cultured for $36 \mathrm{~h}$ at $16^{\circ} \mathrm{C}$ on $100 \mathrm{~mm}$ NGM plates containing OP50 and drugs, upshifted to $23^{\circ} \mathrm{C}$, and incubated at that temperature for another $32 \mathrm{~h}$. The worms were then collected in $1 \mathrm{x}$ phosphate-buffered saline (PBS) $(8 \mathrm{~g} \mathrm{NaCl}, 0.2 \mathrm{~g} \mathrm{KCl}, 1.44 \mathrm{~g}$ $\mathrm{Na}_{2} \mathrm{HPO}_{4}$, and $\left.0.24 \mathrm{~g} \mathrm{KH}_{2} \mathrm{PO}_{4}\right)$. The total protein was isolated with ice-cold radioimmunoprecipitation assay (RIPA) lysis buffer containing $1 \mathrm{x}$ protease inhibitor and 1x phosphatase inhibitor cocktail and identified by using a Tris-Tricine gel (each lane was loaded $40 \mu$ g protein) [11]. The $\mathrm{A} \beta$ protein levels were detected with $6 \mathrm{E} 10$ monoclonal antibody $(1: 500$; BioLegend). Species-specific $\beta$-actin was the internal control detected with mouse $\beta$-actin monoclonal antibody (60008-1Ig; $1: 2000$; Proteintech $\left.{ }^{\circledR}\right)$. Anti-mouse IgG HRP-linked antibody was the secondary antibody (No. 7076, 1:3000; Cell Signaling Technology). Blots were visualized by standard enhanced chemiluminescence (ECL; NCI4106; Thermo Fisher). The protein signals were quantified with Gel-Pro Analyzer 4.

2.8. Chemotaxis Learning Assay. Equal volumes (on demand) of $1 \mathrm{M}$ sodium acetate and $1 \mathrm{M}$ sodium azide were blended and used as an attractant. The control odorant was a mixture of $1 \mathrm{M}$ sodium azide and sterile water. Synchronized CL2355 and control strain CL2122 larvae were cultured on either an untreated or drug-loaded NGM plate at $16^{\circ} \mathrm{C}$ until L3 $(\sim 36 \mathrm{~h})$ and upshifted to $23^{\circ} \mathrm{C}$ for another $36 \mathrm{~h}$. The worms were collected, and the OP50 with M9 Buffer $\left(3 \mathrm{~g} \mathrm{KH}_{2} \mathrm{PO}_{4}\right.$, $6 \mathrm{~g} \mathrm{Na}_{2} \mathrm{HPO}_{4}, 5 \mathrm{~g} \mathrm{NaCl}, 1 \mathrm{~mL} 1 \mathrm{M} \mathrm{MgSO}_{4}$, and $\mathrm{ddH}_{2} \mathrm{O}$ to make up $1 \mathrm{~L}$ ) were cleared out. 40_60 worms were placed in the center of a clear $10-\mathrm{cm}$ NGM plate, $10 \mu \mathrm{L}$ attractant was quickly dropped onto one side of the plate, and $10 \mu \mathrm{L}$ control odorant was dropped onto the other side [12]. After $1 \mathrm{~h}$, the number of worms near each spot was recorded and the chemotaxis index was calculated as follows: chemotaxis index ( $\mathrm{CI})=($ number of worms on attractant side - number of worms on the control side)/total number of worms.

2.9. Fluorescence Assay. Synchronized BC12921 worms were cultured in 96-well plates containing OP50. Drugs were administered at L4, and the worms on day 4 of adulthood were collected. The OP50 and drugs were replaced with M9, and the worms were transferred to a clear $35 \mathrm{~mm}$ NGM plate. The worms were then transferred to a black 96-well plate containing $200 \mu \mathrm{L}$ M9 buffer (10 worms/well, 
60 worms/treatment). Relative fluorescence was detected and quantified in a SpectraMax ${ }^{\circledR}$ ID5 multi-mode microplate reader at $485 \mathrm{~nm}$ excitation and $535 \mathrm{~nm}$ emission.

2.10. ROS Assay. The CL4176 and CL802 worms were synchronized. L1 larvae were exposed to either SCP-Oil or dimethyl sulphoxide (DMSO) in $35 \mathrm{~mm}$ NGM plates at $16^{\circ} \mathrm{C}$ for $36 \mathrm{~h}$ and upshifted to $23^{\circ} \mathrm{C}$ for $32 \mathrm{~h}$; the worms were harvested and washed thrice with M9 to remove the OP50 and drugs. The worms were then transferred to a black 96well plate containing $120 \mu \mathrm{L}$ of $1 \%$ Tween-20 in M9 (15/well). Then, $8.0 \mu \mathrm{L}$ of $50 \mu \mathrm{M}$ 2,7-dichlorofluorescein diacetate $\left(\mathrm{H}_{2} \mathrm{DCFDA}\right)$ (Sigma) was rapidly added. The black plate was incubated at $37^{\circ} \mathrm{C}$ for $2 \mathrm{~h}$; subsequently, the fluorescence intensity was detected every $20 \mathrm{~min}$ for $2 \mathrm{~h}$ using a SpectraMax ${ }^{\circledR}$ ID5 microplate reader with excitation/emission at $485 \mathrm{~nm} / 535 \mathrm{~nm}$.

2.11. Total RNA Isolated and $q R T-P C R$. Starting at L1, synchronized CL4176 worms were fed with OP50 and drugs at $16^{\circ} \mathrm{C}$ for $36 \mathrm{~h}$ and upshifted to $23^{\circ} \mathrm{C}$ for $32 \mathrm{~h}$. The worms were then harvested, washed twice with PBS to remove the OP50 and drugs, washed 3-5 times with diethylpyrocarbonate (DEPC) sterile water, and frozen at $-80^{\circ} \mathrm{C}$ for $2 \mathrm{~h}$. Total RNA was isolated by TRIzol methods [13] and converted to cDNA with an All-in-One cDNA synthesis supermix kit (No. B24403; Bimake). Quantitative real-time PCR (qRTPCR) was performed using a $2 \times$ SYBR Green qPCR master mix kit (No. B21202; Bimake). The qRT-PCR operating conditions were as follows: $95^{\circ} \mathrm{C}$ for $5 \mathrm{~min}$, followed by 40 cycles of $95^{\circ} \mathrm{C}$ for $15 \mathrm{~s}$, and $60^{\circ} \mathrm{C}$ for $45 \mathrm{~s}$. The melting curve was plotted under $95^{\circ} \mathrm{C}$ for $15 \mathrm{~s}, 60^{\circ} \mathrm{C}$ for $1 \mathrm{~min}$, and $95^{\circ} \mathrm{C}$ for $15 \mathrm{~s}$ followed by cooling and maintenance at $4^{\circ} \mathrm{C}$. $\beta$-Actin was the housekeeping gene. The transcription levels were analyzed by the $2^{-\Delta \Delta \mathrm{Ct}}$ method. The primers used in this assay are listed in Supplementary Table S7.

2.12. Serotonin Sensitivity Assay. The L1 of CL2355 and its control strain CL2122 were treated with or without drugs, maintained at $16^{\circ} \mathrm{C}$ for $36 \mathrm{~h}$, and then moved to $23^{\circ} \mathrm{C}$ for $36 \mathrm{~h}$. The worms were collected and washed thrice in M9 buffer to remove the $E$. coli and drugs and then transferred to a 96 -well-plate containing $200 \mu \mathrm{L}$ of $5 \mathrm{mg} / \mathrm{mL}$ serotonin dissolved in M9. Active worms were recorded after $24 \mathrm{~h}$. At least three independent assays were conducted.

2.13. Statistical Analysis. At least three independent experiments were performed per assay. Results were calculated and analyzed by Student's $t$-test. $P<0.05$ was consider statistically significant.

\section{Results}

3.1. SCP-Oil Retards A $\beta$-Induced Paralysis in C. elegans. Extracellular $\beta$-amyloid $(\mathrm{A} \beta)$ deposition is the main $\mathrm{AD}$ pathogenesis, which is neurotoxic and myotoxic [14]. To determine whether SCP-Oil protects against $\mathrm{A} \beta$-induced toxicity in vivo, we assessed the efficacy of SCP-Oil on delaying $A \beta$-induced paralysis in transgenic CL4176 worms expressing temperature-induced human $\mathrm{A} \beta$ protein. We treated the worms with $0-1.0 \mathrm{mg} / \mathrm{mL}$ SCP-Oil in 96 -well plates at $16^{\circ} \mathrm{C}$ for $4 \mathrm{~d}$. The results showed that SCP-Oil < $1.0 \mathrm{mg} / \mathrm{mL}$ had no effect on nematodes' lifespan; it was suggested that SCP-Oil $<1.0 \mathrm{mg} / \mathrm{mL}$ was not toxic to the worms (Figure 1(a)). We then performed a paralysis assay on CL4176 worms using 0, 0.001, 0.01, 0.1, 0.4, and $1.0 \mathrm{mg} / \mathrm{mL}$ SCP-Oil. Our results showed that SCP-Oil delayed paralysis in CL4176 worms in a dose-dependent manner (Figure 1(b) and Table S1). Further, the $\mathrm{PT}_{50}$ for worms treated with $1 \mathrm{mg} / \mathrm{mL}$ SCP-Oil and the untreated worms were $5.70 \pm$ $0.20 \mathrm{~h}$ and $3.25 \pm 0.05 \mathrm{~h}$, respectively; $1 \mathrm{mg} / \mathrm{mL}$ SCP-Oil significantly extended the $\mathrm{PT}_{50}$ by up to $75.39 \%$ relative to the untreated control (Table S1). Therefore, $1 \mathrm{mg} / \mathrm{mL}$ SCPOil was used in the subsequent assays. Overall, the above results suggested that none of the tested SCP-Oil concentrations was toxic to the worms and all could potentially protect them against $A \beta$-induced damage.

\subsection{SCP-Oil Enhances Olfactory Learning and Serotonin} Sensitivity in Nematodes with Neuronal A $\beta$ Expression. CL2355 is a transgenic strain in which $A \beta$ was expressed in their neuronal cells; it was showed deficits in chemotaxis and associative learning skills [15]. To investigate the protective effects of SCP-Oil on the neurological functions, we determined olfactory adaptation-related learning in this strain. The chemotaxis assay indicated that $1 \mathrm{mg} / \mathrm{mL}$ SCPOil significantly increased the number of worms on the attractant side of the plate (Figure 2(a)). The chemotaxis indexes for CL2122 control strain and the untreated CL2355 worms were $0.35 \pm 0.01$ and $-0.13 \pm 0.02$, respectively (Table S2), which suggested that worms with panneuronal human $A \beta$ expression did exhibit severe cognitive deficit. However, the SCP-Oil treatment significantly increased the value of CI to $0.12 \pm 0.01$ (Figure $2(\mathrm{a})$ and Table S2). So, SCP-Oil obviously exhibited a protective effect on the neurological functions of worms.

Neurotransmitter serotonin plays an important role in locomotion, cognition, and learning-related behavioral plasticity in C. elegans [16]. Here, we incubated the worms in $5 \mathrm{mg} / \mathrm{mL}$ exogenous serotonin for $24 \mathrm{~h}$ and recorded the number of active individuals. Figure 2(b) shows that $\sim 27.40 \pm 1.70 \%$ of the worms were still alive after treated with $1 \mathrm{mg} / \mathrm{mL}$ SCP-Oil, but only $13.34 \pm 1.50 \%$ of the control worms had survived (Table S3). Moreover, exogenous serotonin had a negligible effect on the CL2122 control (50.56 $\pm 1.11 \%$; Figure 2(b) and Table S3).

Hence, $1 \mathrm{mg} / \mathrm{mL}$ SCP-Oil can obviously improve learning behavior and augment serotonergic excitability against $A \beta$-induced deficits in the neurological functions.

3.3. SCP-Oil Decreases A $\beta$ Aggregation in C. elegans. Given that SCP-Oil could effectively delay paralysis of CL4176 worms, we evaluated the effect of SCP-Oil on $A \beta$ transcription and protein levels. Relative to the untreated, the $\mathrm{A} \beta$ transcription level was decreased by 0.56 -fold in nematodes treated with $1 \mathrm{mg} / \mathrm{mL}$ SCP-Oil (Figure 3(a)). The amyloid protein levels indicated that $1 \mathrm{mg} / \mathrm{mL}$ SCP-Oil can significantly decrease $\mathrm{A} \beta$ aggregation in worms; quantitative data analysis showed that $\mathrm{A} \beta$ oligomers and monomers were 


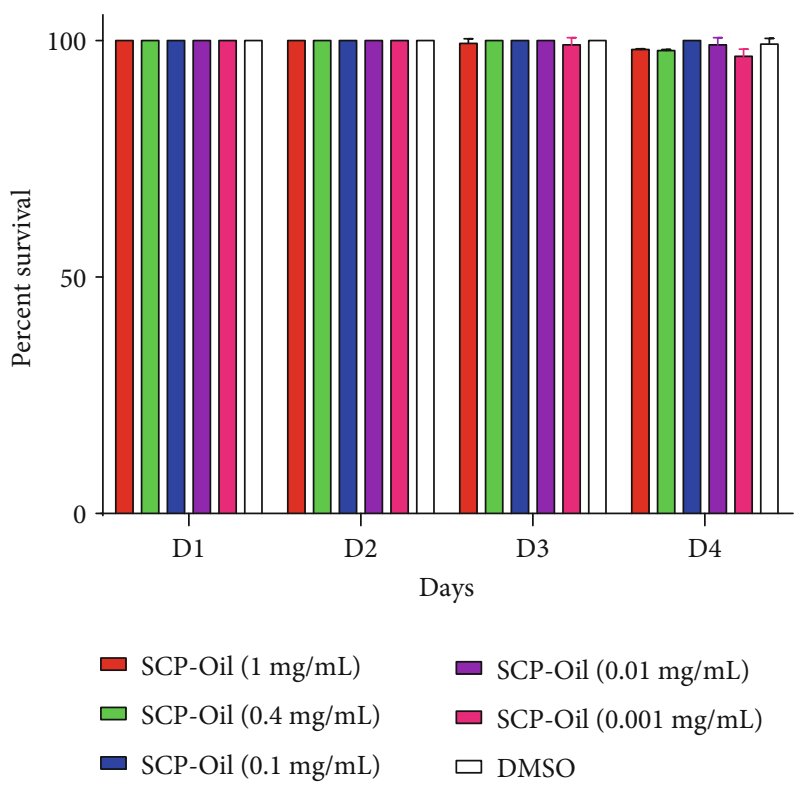

(a)

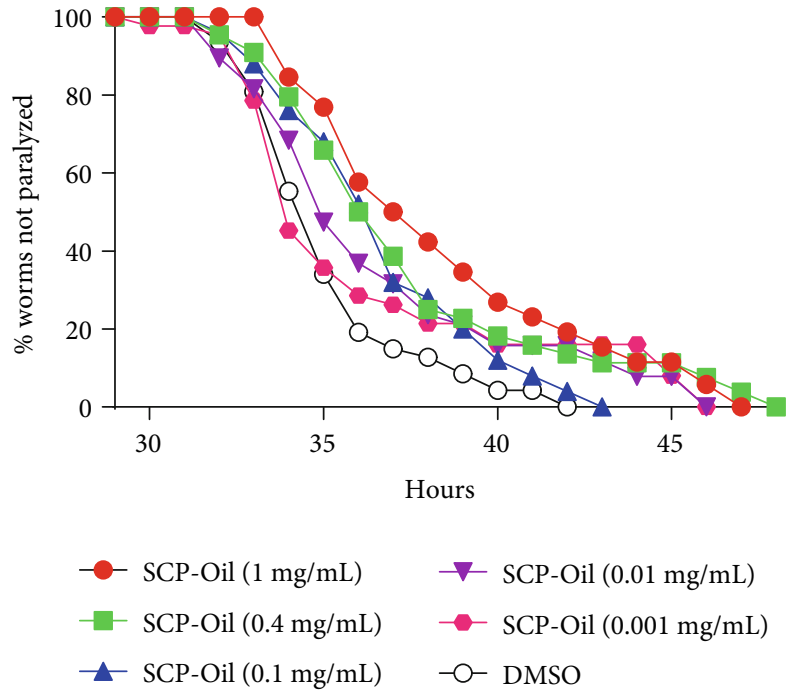

(b)

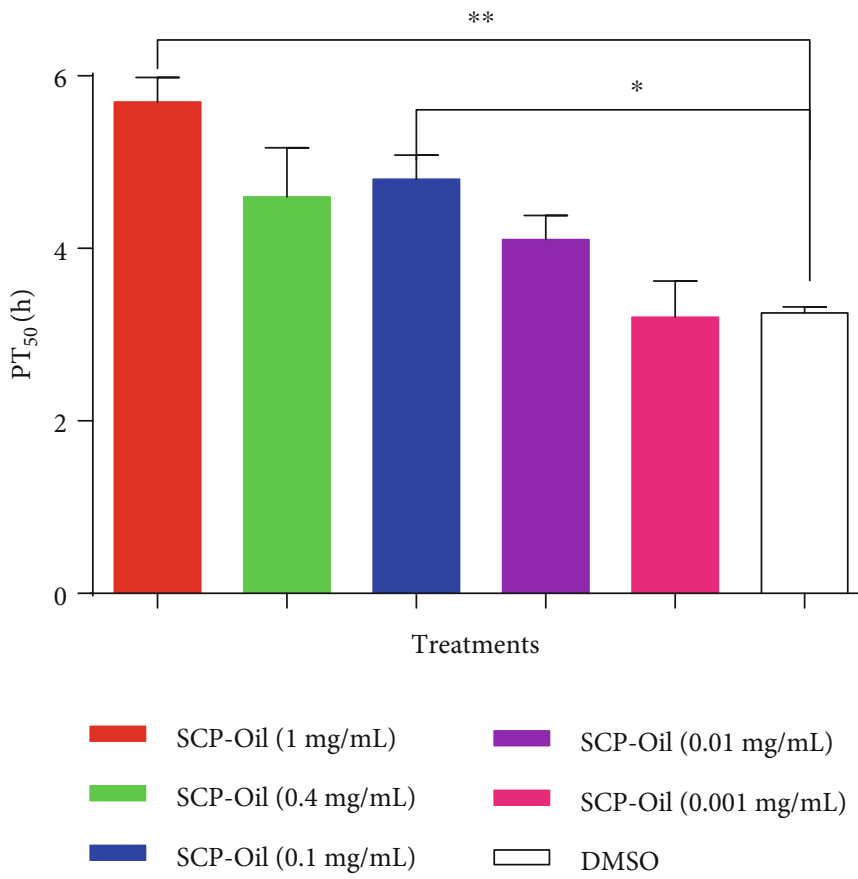

(c)

Figure 1: Various SCP-Oil concentrations impeded $A \beta$ induced paralysis in C. elegans. (a) Percent survival of CL4176 at $16^{\circ} \mathrm{C}$ in $96-$ well plates containing $0,0.001,0.01,0.1,0.4$, and $1 \mathrm{mg} / \mathrm{mL}$ SCP-Oil. (b) Percentage of worms not paralyzed at the various SCP-Oil concentrations. (c) $\mathrm{PT}_{50}$ for untreated worms and those treated with SCP-Oil. Data were analyzed by Student's $t$-test. Error bars indicate the means \pm SD. ${ }^{* *} P<0.01$ and ${ }^{*} P<0.05$.

remarkably reduced by $\sim 39.10 \%$ and $40.07 \%$, respectively, in nematodes treated with $1 \mathrm{mg} / \mathrm{mL}$ SCP-Oil (Figures 3(b)$3(\mathrm{~d})$ ). Therefore, SCP-Oil resisted $A \beta$-induced damage in C. elegans by downregulating $A \beta$ transcription and decreasing amyloid protein expression.

3.4. SCP-Oil Reduces polyQ Accumulation in C. elegans. Abnormal polyglutamine (polyQ) aggregation disrupts cellu- lar proteostasis, triggers cytopathy, and induces neurodegenerative diseases, aggregation of polyQ protein elevating amyloidogenic processing of amyloid precursor protein by upregulating $\beta$-site amyloid precursor protein-cleaving enzyme 1 [17]. To determine whether SCP-Oil mitigates the accumulation of other abnormal proteins in vivo, we measured polyQ accumulation in AM140 strain. Fluorescence images disclosed there was less polyQ aggregation in 


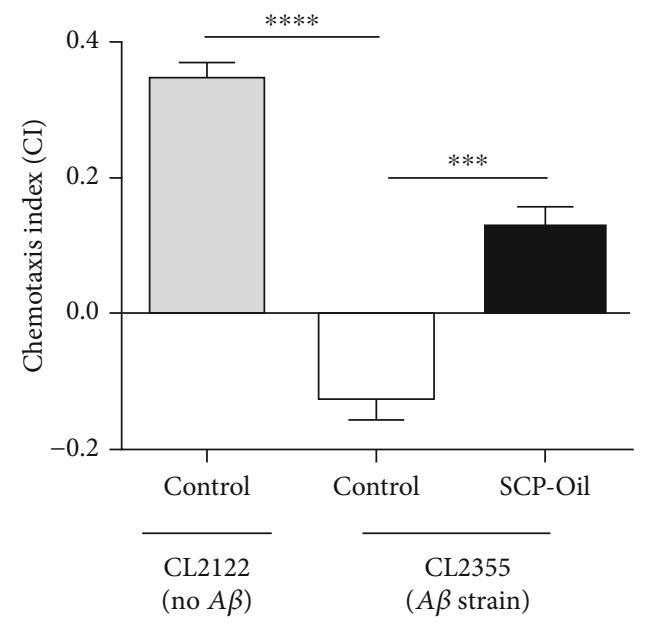

(a)

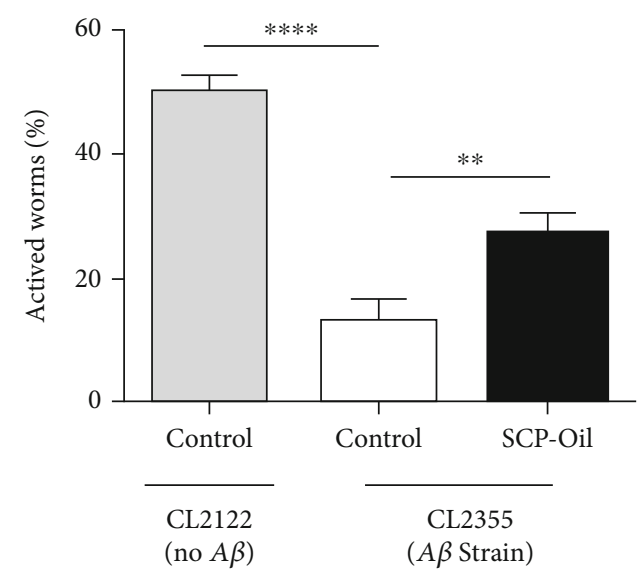

(b)

FIGURE 2: SCP-Oil enhanced chemotaxis and serotonin sensitivity in pan-neuronal $A \beta$ transgenic worms. (a) Chemotaxis in CL2355 and its control strain CL2122. (b) SCP-Oil increased serotonin sensitivity relative to the untreated control group. Three independent experiments were conducted per assay. Values are the means \pm SD. ${ }^{* * *} P<0.0001,{ }^{* * *} P<0.001$, and ${ }^{* *} P<0.01$.

worms treated with $1 \mathrm{mg} / \mathrm{mL}$ SCP-Oil than there was in control worms (Figure 4(a)). Quantitative data analysis revealed that the polyQ level was $24.85 \%$ lower in the treated group than it was in the control (Figure 4(b) and Table S4). The results suggested that $1 \mathrm{mg} / \mathrm{mL}$ SCP-Oil could significantly alleviate the proteotoxic stress induced by polyQ aggregation.

3.5. SCP-Oil Decreases A $\beta$-Induced ROS Accumulation in C. elegans. $\mathrm{A} \beta$ aggregation causes mitochondrial dysfunction which, in turn, leads to the release of reactive oxygen species (ROS). Excessive ROS potentiates A $\beta$ toxicity and promotes neuroinflammation [18]. We measured the ROS levels in AD worms with an $\mathrm{H}_{2}$ DCFDA kit and found that ROS levels were relatively lower in the CL802 control (Figure 5(a)). Unlike CL4176, CL802 does not express human $A \beta$ in its muscle cells. In contrast, the cellular ROS level was extremely high in untreated CL4176 (Figure 5(a)). After being treated with $1 \mathrm{mg} / \mathrm{mL}$ SCP-Oil, the intracellular ROS concentration in CL4176 was significantly reduced by $13.55 \%$ compared with the ROS level of the control group (Figure 5(b) and Table S5). Thus, SCP-Oil could mitigate ROS accumulation and ameliorate cellular damage caused by $\mathrm{A} \beta$.

3.6. Protection Effects Provided by SCP-Oil Is AutophagyDependent. In order to clarify the underlying signal pathway involved in the protection effects of SCP-Oil in C. elegans, we selected some key transcription factors involved in aging, stress resistance, and protein homeostasis, including daf-2 and daf-16 that play an important role in regulating lifespan and stress resistance [19]; skn-1, hsf-1, and sir-2.1 that participate in stress resistance and protein homeostasis [20, 21]; and bec-1,vps-34, unc-51, lgg-1, and other genes that are vital for the autophagy pathway in C. elegans [22].

Our results showed that SCP-Oil could not increase the expression of daf-2 or daf-16, but $h s f-1$ and sir-2.1 were obviously upregulated, 1.72 - and 1.85 -fold higher than the con- trol group, respectively (Figure 6(a)), that means protection effects of SCP-Oil partly depend on $h s f-1$ and sir-2.1 genes.

Moreover, the autophagy-related genes of the SCP-Oiltreated worms were dramatically upregulated. The expression levels of bec-1,vps-34, and unc-51 were $2.28 \pm 0.02$ -fold, $3.39 \pm 0.06$-fold, and $3.69 \pm 0.02$-fold higher, respectively, in the treated worms than they were in the control $(1.00 \pm 0.01)$ (Figure 6(a)). Besides, both $\operatorname{lgg}-1$ and $\operatorname{lgg}-2$ (homologues of mammalian LC3 associated with autophagosome and autolysosome formation) were at least 3.84-fold and 2.55-fold higher in the SCP-Oil-treated worms than they were in the control (Figure 6(a)).

P62/SQSTM1 is a ubiquitin- and LC3-binding protein and is degraded by autophagy. In vivo, P62/SQSTM1 accumulation is commonly accompanied by reduced autophagy [23]. The observed upregulation of autophagy-associated genes suggested that SCP-Oil could enhance autophagy activity in $\mathrm{AD}$ worms. We measured the $\mathrm{P} 62$ protein level in BC12921 stain expressing SQST-1::GFP protein. A fluorescence intensity assay demonstrated that $\mathrm{P} 62$ protein expression was $>60 \%$ lower in the SCP-Oil-treated worms than it was in the control (Figure 6(c)). This finding indicated that autophagy was very active in nematodes treated with SCPOil. The above results strongly indicated that $1 \mathrm{mg} / \mathrm{mL}$ SCP-Oil showing protective effect against $A \beta$-induced injury was dependent on autophagy pathway.

\section{Discussion}

The pathogenic mechanisms of Alzheimer's disease (AD) involve the deposition of abnormally misfolded proteins, amyloid $\beta$ protein $(A \beta)$, and tau protein. $A \beta$ comprises senile plaques, and tau aggregates form neurofibrillary tangles, both of which are hallmarks of $\mathrm{AD}$. Although it was reported that $\beta$-asarone, a major component of SCP, showed protection against neuronal damage induced by amyloid- $\beta$ in rats $[5$, $6]$, the underlying molecular mechanism of SCP is still 


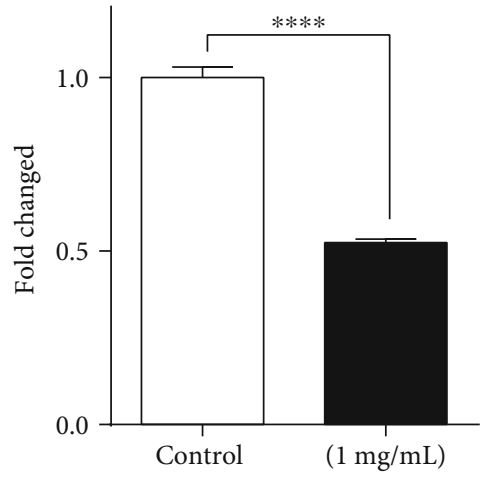

(a)

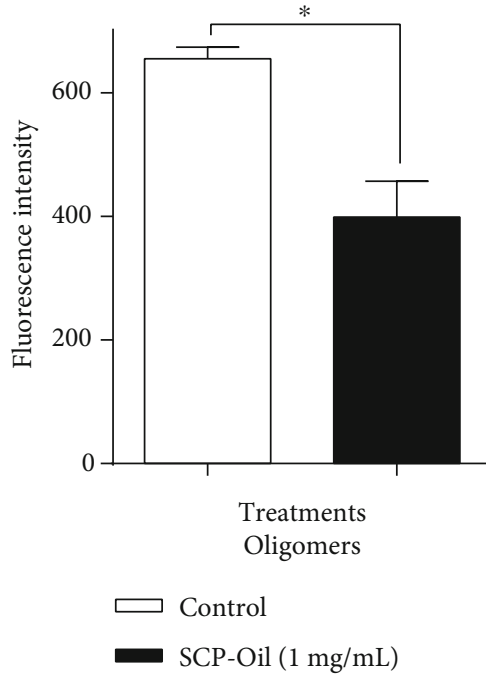

(c)

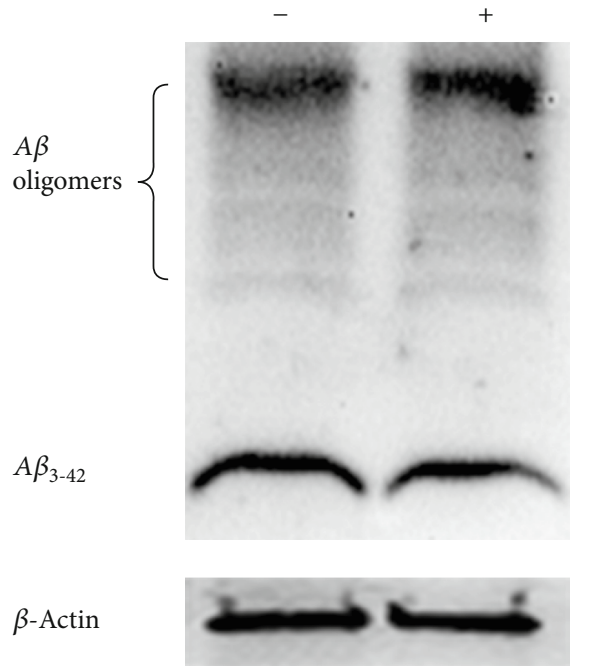

(b)

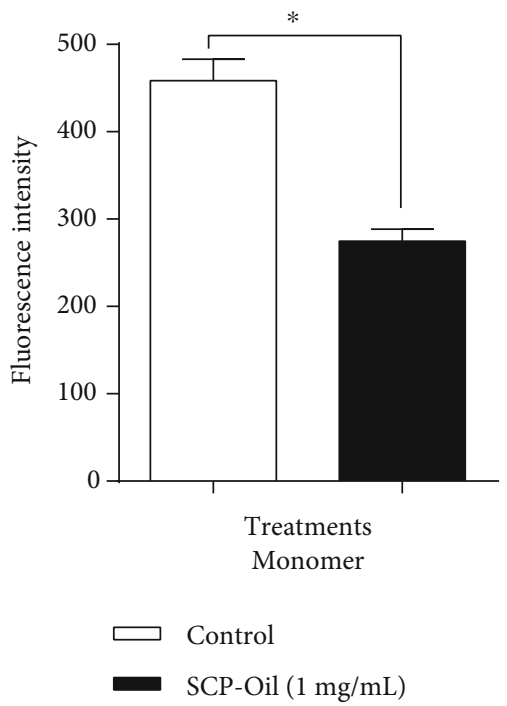

(d)

Figure 3: SCP-Oil decreased the $A \beta$ transcript and protein levels in CL4176 nematodes. (a) The $1 \mathrm{mg} / \mathrm{mL}$ SCP-Oil treatment decreased $A \beta$ expression in CL4176. (b) Western blot of $\mathrm{A} \beta$ oligomers and monomer in CL4176 following SCP-Oil treatment. $\beta$-Actin was the internal reference for normalization. (c) A $\beta$ oligomers quantification by Gel-Pro. (d) A $\beta$ monomer quantification in CL4176 nematodes. The assay was repeated at least thrice. Error bars represent SD. ${ }^{* * *} P<0.0001$ and ${ }^{*} P<0.05$.

unclear. Here, our experiment results showed that SCP-Oil can remarkably ameliorate $A \beta$-induced paralysis in worms expressing $A \beta$ protein in their muscle cells compared with DMSO control or vehicle control (Figures 1(b) and 1(c) and S1). An immunoassay disclosed that SCP-Oil decreases $\mathrm{A} \beta$ oligomers and monomer protein levels (Figures 3(b)$3(\mathrm{~d})$ ), and the $\mathrm{A} \beta$ transcription level was significantly decreased in nematodes treated with $1 \mathrm{mg} / \mathrm{mL}$ SCP-Oil (Figure 3(a)). The above results furtherly confirmed that SCP-Oil is the main component of SCP and has an inhibitory effect on the toxicity of $\mathrm{A} \beta$ protein. Additionally, we found that SCP-Oil improves chemotaxis-related learning and serotonin-associated excitability in worms expressing $A \beta$ in neuron cells (Figure 2), which suggested that SCP-Oil has a protective effect on neuron damage induced by $A \beta$ protein.
Moreover, SCP-Oil can significantly reduce the deposition of misfolded polyQ protein in AM140 strains (Figure 4). These results suggested that SCP-Oil has the effect of maintaining the homeostasis of misfolded proteins and shows the potential to develop a therapeutic for AD.

Oxidative stress has been recognized as a contributing factor in the progression of multiple neurodegenerative diseases including $\mathrm{AD}$ [24]. Abnormal proteins in turn could exacerbate ROS production (Figure 5(a)), thereby contributing to a vicious cycle. We found that SCP-Oil treatment substantially reduced ROS levels in CL4176 strains (Figure 5(b) and Table S5). Generally, increased production of ROS is associated with loss of mitochondrial function. Sir-2.1, a key gene for controlling mitochondrial function [25], was significantly upregulated (Figure 6(a)). Therefore, SCP-Oil 

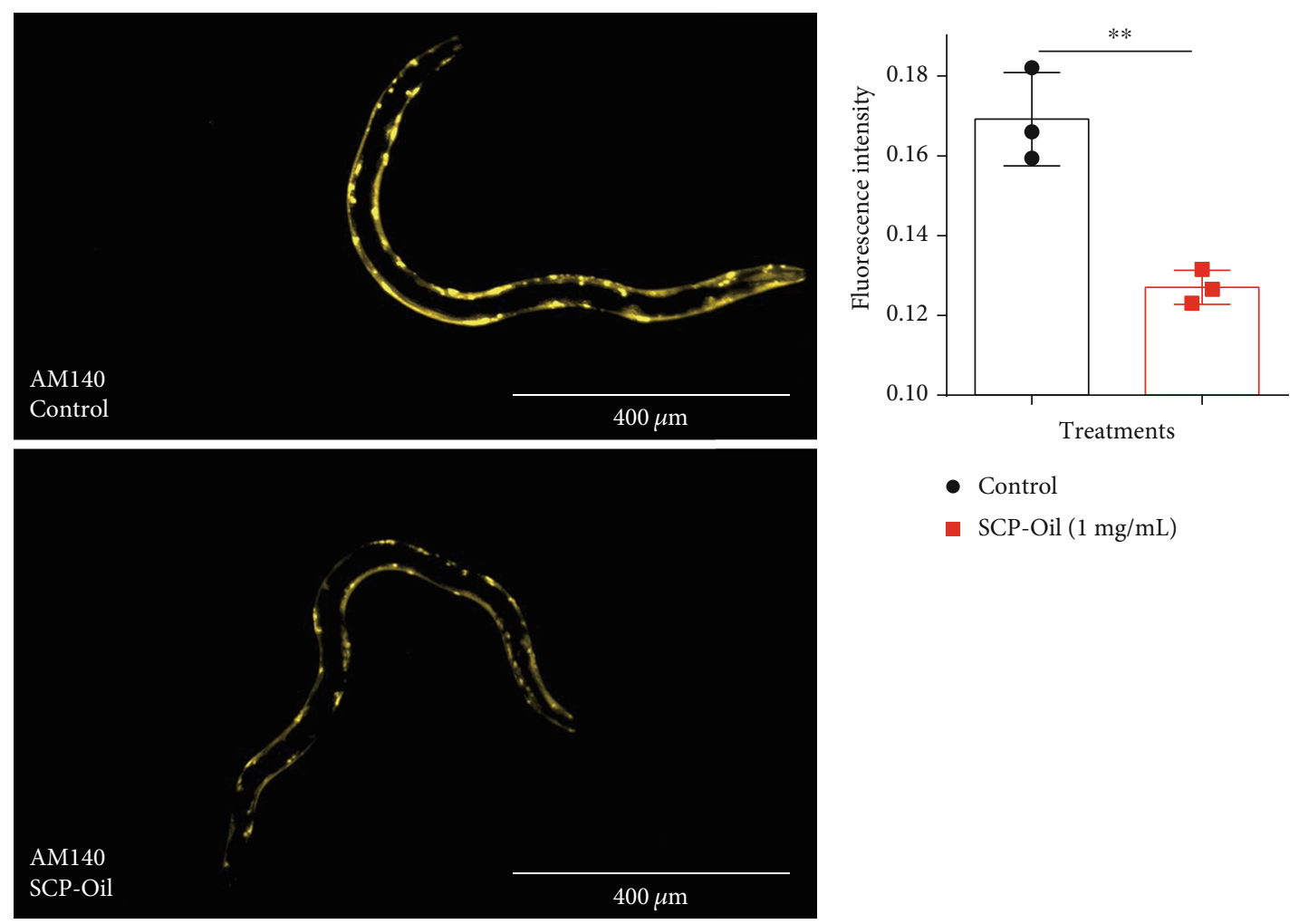

- Control

- SCP-Oil $(1 \mathrm{mg} / \mathrm{mL})$

(a)

(b)

FIGURE 4: SCP-Oil decreased polyQ accumulation in AM140. (a) Representative images of AM140 [unc-54p::Q35::YFP] expressing Q35::YFP in response to no treatment or treatment with $1 \mathrm{mg} / \mathrm{mL}$ SCP-Oil. These images were taken by a fluorescence microscopy. (b) Quantification of YFP fluorescence intensity in worms either untreated or administered $1 \mathrm{mg} / \mathrm{mL}$ SCP-Oil using ImageJ 1.52a. Error bar represents the mean \pm SD for $\geq 3$ independent experiments. Significance was determined by Student's $t$-test. ${ }^{* *} P<0.01 ; n \geq 30$.

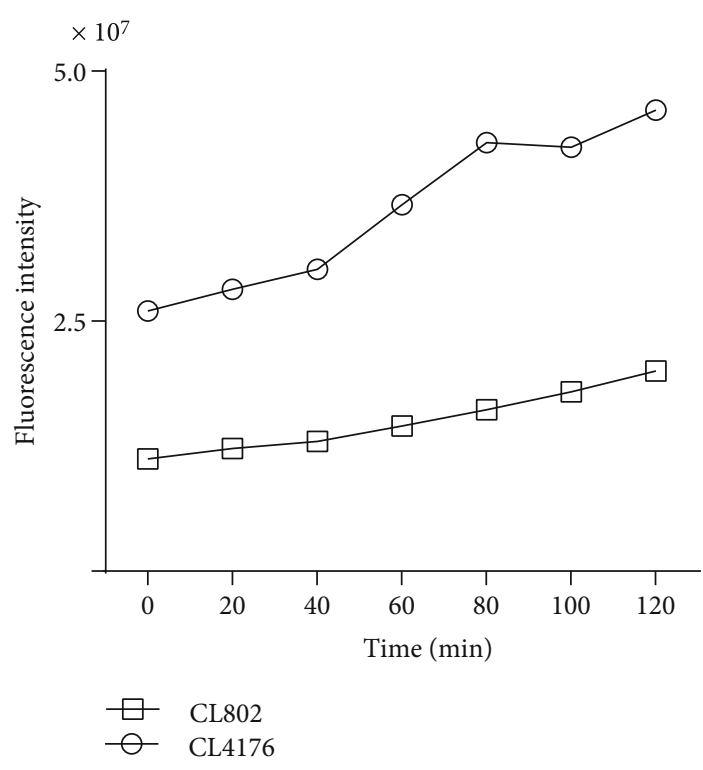

(a)

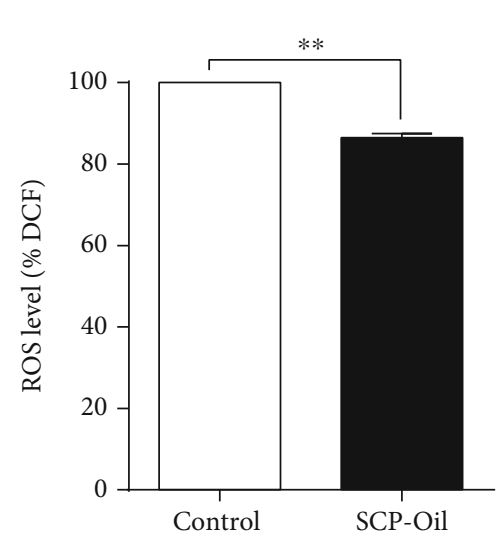

(b)

FIgURE 5: SCP-Oil mitigated $A \beta$-induced ROS accumulation in C. elegans. (a) The ROS fluorescence intensity in CL4176 worms and its control strain CL802 worms. (b) The $1 \mathrm{mg} / \mathrm{mL}$ SCP-Oil treatment attenuated $A \beta$-induced ROS formation in transgenic CL4176 worms. The control group fluorescence intensity was $100 \%$ and that for the treatment group was calculated relative to that of the control. Error bars represent the means \pm SD. ${ }^{* *} P<0.01 ; n \geq 60$. 


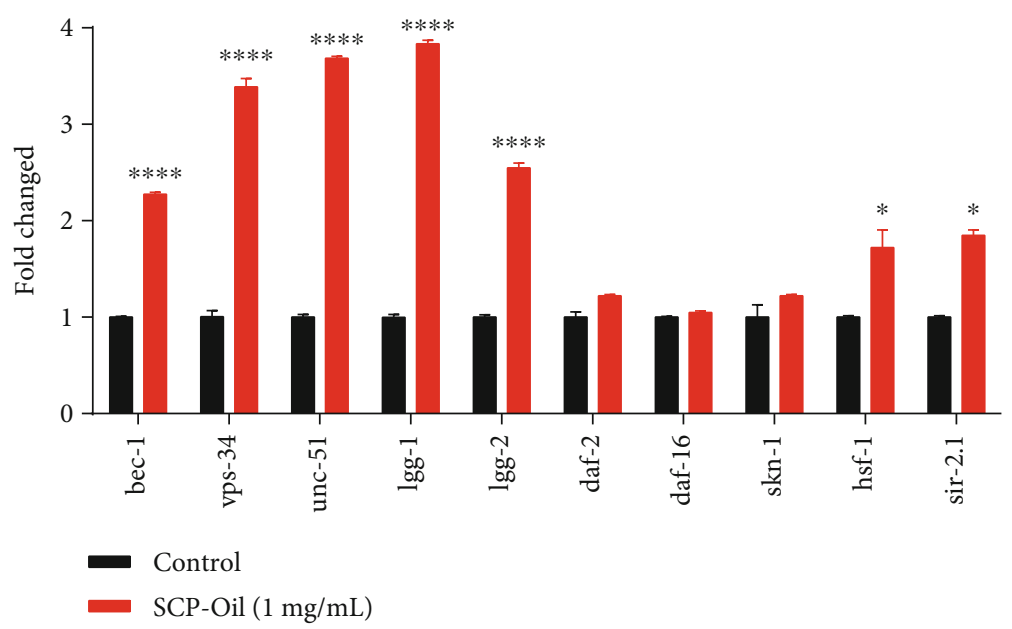

(a)
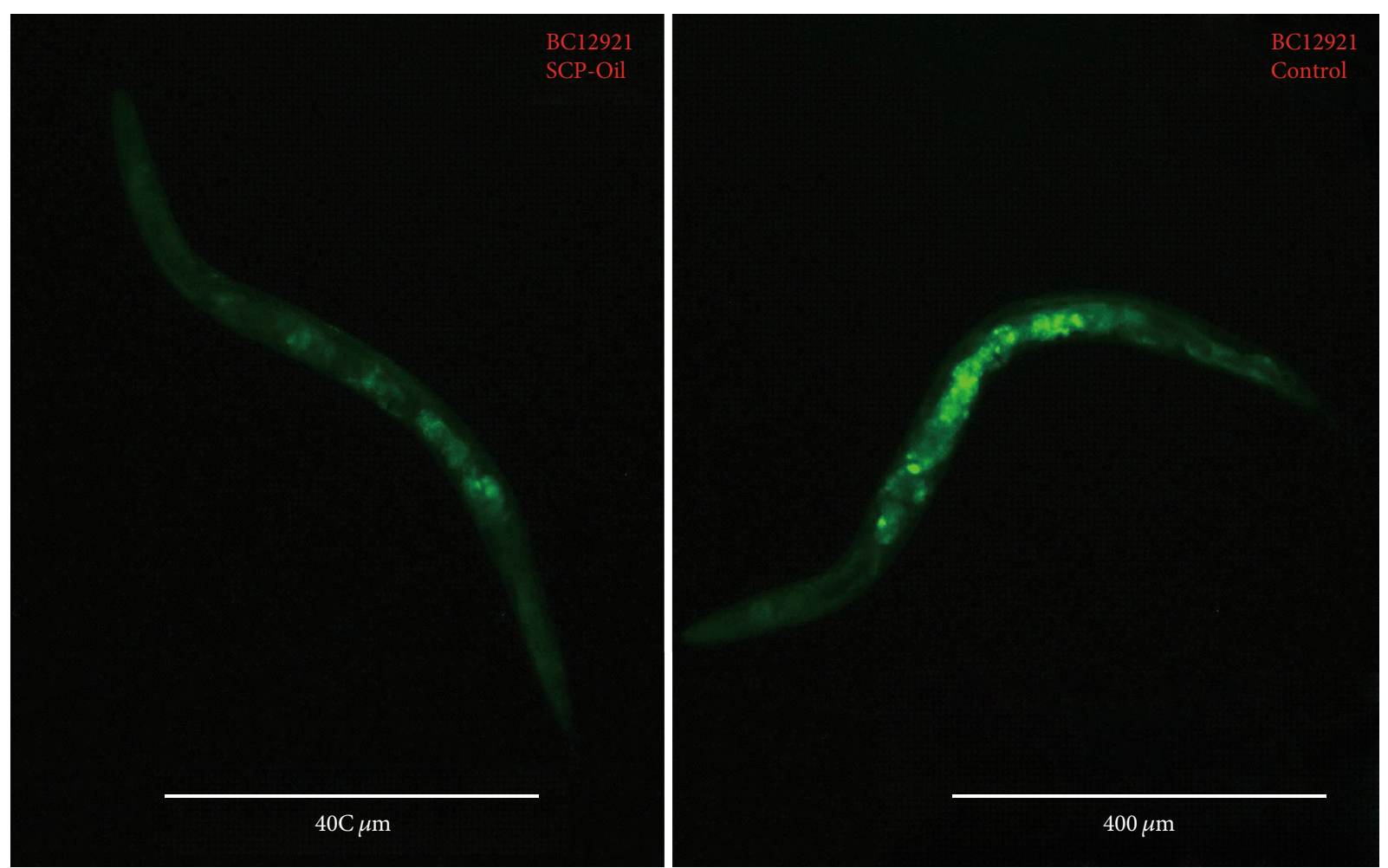

(b)

Figure 6: Continued. 


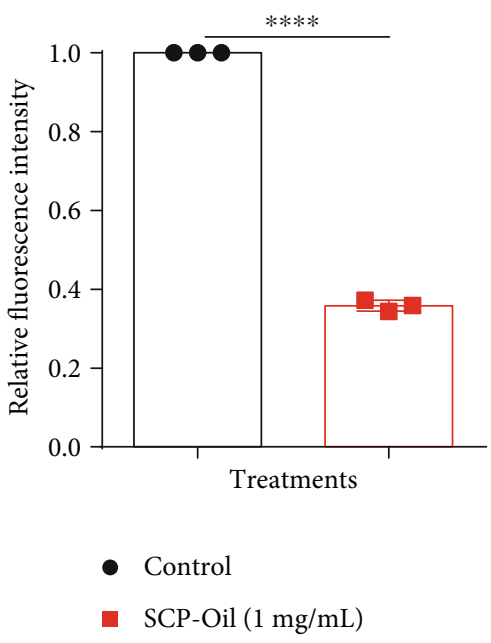

(c)

FIGURE 6: SCP-Oil protection against $A \beta$-induced damage was mediated by the autophagy pathway. (a) Gene mRNA transcription levels after treatment with $1 \mathrm{mg} / \mathrm{mL}$ SCP-Oil. (b) P62/SQSTM-1 substrate levels in BC12921 worms either untreated or treated with $1 \mathrm{mg} / \mathrm{mL}$ SCP-Oil. (c) Fluorescence intensity analysis of BC12921 cultured with or without SCP-Oil. All assays were performed at least twice. Data were analyzed by Student's $t$-test. Error bar indicates the mean \pm SD. ${ }^{* * *} P<0.0001$ and ${ }^{*} P<0.05$.

exerting its protective efficacy against $A \beta$-induced injury partly depends on regulating mitochondrial function to decrease the level of ROS in vivo.

Autophagy, the main conserved pathway for the degeneration of aggregated proteins, $A \beta$, tau, and dysfunctional organelles in the cell, has been discovered to be involved in the pathological changes of $\mathrm{AD}$ [3]. Due to the fact that SCP-Oil could significantly reduce the expression of $A \beta$ and polyQ proteins in worms, we inferred that autophagy may make a contribution for this beneficial effect of SCPOil. According to the results of autophagy-related genes assay, the mRNA levels of key genes $(\operatorname{lgg}-1, \operatorname{lgg}-2$, bec-1, vps34, and unc-51) were remarkably upregulated (Figure 6(a)). Moreover, P62 protein, one of the best-known autophagic substrates, was obviously reduced after treatment with SCPOil (Figure 6(c) and Table S6). These findings suggested that the autophagy pathway was involved in the protection against abnormal $\mathrm{A} \beta$ and polyQ protein-induced toxicity.

Autophagy is induced in multiple tissues of Caenorhabditis elegans following HSF-1 overexpression, and downregulation of HSF-1 activity exacerbates misfolded and unfolded protein aggregation [26]. Our present study demonstrated that SCP-Oil significantly upregulated the $h s f-1$ transcription level (Figure 6(a)). Additionally, sir-2.1 not only participates in oxidative stress but also induces autophagy activity to reduce abnormal protein aggregation and toxicity [27]. Taken together, our results revealed that the effect of SCPOil maintaining protein homeostasis is dependent on the autophagy pathway regulated partly by $h s f-1$ and $s i r-2.1$ genes.

\section{Conclusions}

In summary, our results confirmed that SCP-Oil is the main component of SCP showing a protection effect against abnormal proteins in worms. We further clarified the pharmaco- logical action mechanism of SCP-Oil and showed that it reduces $\mathrm{A} \beta$ and polyQ deposition through the targeting autophagy pathway. In the recent few years, much progress has been made in finding autophagy regulators from natural products, which provides new insights to develop treatment strategy for $\mathrm{AD}$ by targeting autophagy. SCP-Oil could be an alternative drug for anti-AD.

$\begin{array}{ll}\text { Abbreviations } & \\ \text { AD: } & \text { Alzheimer's disease } \\ \text { A } \beta: & \text { Beta-amyloid peptide } \\ \text { C. elegans: } & \text { Caenorhabditis elegans } \\ \text { CGC: } & \text { Caenorhabditis Genetics Center } \\ \text { CI: } & \text { Chemotaxis index } \\ \text { DEPC: } & \text { Diethylpyrocarbonate } \\ \text { E. coli: } & \text { Escherichia coli } \\ \text { GFP: } & \text { Green fluorescent protein } \\ \text { DMSO: } & \text { Dimethyl sulphoxide } \\ \text { H } 2 \text { DCFDA: } & \text { Dichlorofluorescein diacetate } \\ \text { HPLC: } & \text { High-performance liquid } \\ & \text { chromatography } \\ \text { NGM: } & \text { Nematode growth medium } \\ \text { PBS: } & \text { Phosphate-buffered saline } \\ \text { PolyQ: } & \text { Polyglutamine } \\ \text { qPCR/qRT-PCR: } & \text { Real-time quantitative polymerase chain } \\ & \text { reaction } \\ \text { ROS: } & \text { Reactive oxygen species } \\ \text { SCP: } & \text { Acorus tatarinowii Schott } \\ \text { SCP-Oil: } & \text { Essential oil of Acorus tatarinowii Schott. }\end{array}$

\section{Data Availability}

It can be found in Supplementary Materials file. 


\section{Conflicts of Interest}

The authors declare that they have no known competing financial interests or personal relationships that could be construed as having influenced the research reported in this paper.

\section{Authors' Contributions}

Xin-yan Chen and De-chun Liao contributed equally to this work.

\section{Acknowledgments}

The authors thank the CGC (Minneapolis, MN, USA) for providing the nematode strains tested in this study and the National Natural Science Foundation (Grant nos. 31670347, 81001369, and 31170327) for the financial support.

\section{Supplementary Materials}

The supplementary files comprise tabulated data for the paralysis, ROS, polyQ, and other assays. Table S1: SCP-Oil ameliorated $\mathrm{A} \beta$-induced paralysis in C. elegans. Table S2: SCP-Oil enhanced chemotaxis behavior in CL2355. Table S3: SCP-Oil improved 5-HT sensitivity in CL2355. Table S4: SCP-Oil reduced polyQ aggradation in AM140. Table S5: SCP-Oil decreased the ROS level in CL4176. Table S6: the effects of SCP-Oil on autophagy activity in BC12921. Table S7: primer sequences used in Q-PCR. Fig. S1: the neuroprotection of SCP-Oil on A $\beta$-induced or non-A $\beta$-induced toxicity in C. elegans. Fig. S2: comparison of chromatograms of SCP-Oil and standard. (Supplementary Materials)

\section{References}

[1] Z. Arvanitakis, R. C. Shah, and D. A. Bennett, "Diagnosis and management of dementia: review," JAMA, vol. 322, no. 16, pp. 1589-1599, 2019.

[2] M. H. Cho, K. Cho, H. J. Kang et al., "Autophagy in microglia degrades extracellular $\beta$-amyloid fibrils and regulates the NLRP3 inflammasome," Autophagy, vol. 10, no. 10, pp. 1761-1775, 2014.

[3] Q. Zeng, W. Siu, L. Li et al., "Autophagy in Alzheimer's disease and promising modulatory effects of herbal medicine," Experimental Gerontology, vol. 119, pp. 100-110, 2019.

[4] F. H. Zhang, Z. M. Wang, Y. T. Liu et al., "Bioactivities of serotonin transporter mediate antidepressant effects of _Acorus tatarinowii_Schott," Journal of Ethnopharmacology, vol. 241, p. 111967, 2019.

[5] L. Yan, G. Mahady, Y. Qian et al., "The Essential Oil from Acori Tatarinowii Rhizome (the Dried Rhizome of Acorus tatarinowii Schott) Prevents Hydrogen Peroxide-Induced Cell Injury in PC12 Cells: A Signaling Triggered by CREB/PGC- $1 \alpha$ Activation," Evidence-based Complementary and Alternative Medicine, vol. 2020, Article ID 4845028, 12 pages, 2020.

[6] G. Saki, A. Eidi, P. Mortazavi, N. Panahi, and A. Vahdati, "Effect of $\beta$-asarone in normal and $\beta$-amyloid-induced Alzheimeric rats," Archives of Medical Science, vol. 16, no. 3, pp. 699706, 2020.
[7] L. Ma, Y. Zhao, Y. Chen, B. Cheng, A. Peng, and K. Huang, “_Caenorhabditis elegans_as a model system for target identification and drug screening against neurodegenerative diseases," European Journal of Pharmacology, vol. 819, pp. 169$180,2018$.

[8] A. G. Alexander, V. Marfil, and C. Li, "Use of Caenorhabditis elegans as a model to study Alzheimer's disease and other neurodegenerative diseases," Frontiers in Genetics, vol. 5, p. 279, 2014.

[9] S. Brenner, "The genetics of Caenorhabditis elegans," Genetics, vol. 77, no. 1, pp. 71-94, 1974.

[10] V. Dostal and C. D. Link, "Assaying beta-amyloid toxicity using a transgenic C. elegans model," Journal of Visualized Experiments, vol. 44, 2010.

[11] Y. Wu, Z. Wu, P. Butko et al., "Amyloid-beta-induced pathological behaviors are suppressed by Ginkgo biloba extract EGb 761 and ginkgolides in transgenic Caenorhabditis elegans," The Journal of Neuroscience, vol. 26, no. 50, pp. 13102-13113, 2006.

[12] O. Margie, C. Palmer, and I. Chin-Sang, "C. elegans chemotaxis assay," Journal of Visualized Experiments, vol. 74, article e50069, 2013.

[13] R. F. Ketting, M. Tijsterman, and R. H. Plasterk, "Isolation of RNA from C. elegans," CSH Protocol, vol. 2006, 1 pages, 2006.

[14] H. W. Querfurth and F. M. Laferla, "Alzheimer's disease," The New England Journal of Medicine, vol. 362, no. 4, pp. 329-344, 2010.

[15] Y. Ishita, T. Chihara, and M. Okumura, "Serotonergic modulation of feeding behavior in _Caenorhabditis elegans_ and other related nematodes," Neuroscience Research, vol. 154, pp. 9-19, 2020.

[16] S. Ansar, D. M. Merritt, and D. van der Kooy, "Serotonin mediates Caenorhabditis elegans associative learning by indicating presence or absence of food," University of Toronto Journal of Undergraduate Life Sciences, vol. 12, no. 1, pp. 2529, 2018.

[17] J. Suh, D. M. Romano, L. Nitschke et al., "Loss of ataxin-1 potentiates Alzheimer's pathogenesis by elevating cerebral BACE1 transcription," Cell, vol. 178, no. 5, pp. 11591175.e17, 2019.

[18] C. Giorgi, S. Marchi, I. C. M. Simoes et al., "Mitochondria and reactive oxygen species in aging and age-related diseases," International Review of Cell and Molecular Biology, vol. 340, pp. 209-344, 2018.

[19] R. Kaletsky, V. Lakhina, R. Arey et al., “The_C. elegans_adult neuronal IIS/FOXO transcriptome reveals adult phenotype regulators," Nature, vol. 529, no. 7584, pp. 92-96, 2016.

[20] D. A. Garsin, K. M. Glover-Cutter, S. Lin, and T. K. Blackwell, "Integration of the unfolded protein and oxidative stress responses through SKN-1/Nrf," PLoS Genetics, vol. 9, no. 9, article e1003701, 2013.

[21] W. C. Chiang, T. T. Ching, H. C. Lee, C. Mousigian, and A. L. Hsu, "HSF-1 regulators DDL-1/2 link insulin-like signaling to heat-shock responses and modulation of longevity," Cell, vol. 148, no. 1-2, pp. 322-334, 2012.

[22] H. Zhang, J. T. Chang, B. Guo et al., "Guidelines for monitoring autophagy in Caenorhabditis elegans," Autophagy, vol. 11, no. 1, pp. 9-27, 2015.

[23] M. Komatsu, S. Waguri, M. Koike et al., "Homeostatic levels of p62 control cytoplasmic inclusion body formation in 
autophagy-deficient mice," Cell, vol. 131, no. 6, pp. 1149-1163, 2007.

[24] E. Tonnies and E. Trushina, "Oxidative stress, synaptic dysfunction, and Alzheimer's disease," Journal of Alzheimer's Disease, vol. 57, no. 4, pp. 1105-1121, 2017.

[25] L. Mouchiroud, R. H. Houtkooper, N. Moullan et al., "The $\mathrm{NAD}^{+}$/sirtuin pathway modulates longevity through activation of mitochondrial UPR and FOXO signaling," Cell, vol. 154, no. 2, pp. 430-441, 2013.

[26] R. Gomez-Pastor, E. T. Burchfiel, and D. J. Thiele, "Regulation of heat shock transcription factors and their roles in physiology and disease," Nature Reviews. Molecular Cell Biology, vol. 19, no. 1, pp. 4-19, 2018.

[27] B. H. Shin, Y. Lim, H. J. Oh et al., "Pharmacological activation of Sirt1 ameliorates polyglutamine-induced toxicity through the regulation of autophagy," PLoS One, vol. 8, no. 6, p. e64953, 2013. 